\title{
SMEs' Innovation and Export Capabilities: Identification and Characterization of a Common Space Using Data Spatialization
}

\author{
Manon Enjolras ${ }^{* 1}$, Mauricio Camargo ${ }^{1}$, Christophe Schmitt ${ }^{2}$
}

\begin{abstract}
Numerous publications try to identify and test empirically the link between innovation and export to explain firms' competitiveness. But it seems that several ways of thinking coexist, without a real consensus. This article proposes a different approach, by considering innovation and export not in terms of impact of the one on the other, but rather as two complementary activities mobilizing common capabilities (resources, skills, knowledge). These common capabilities represent the capabilities that a company needs to mobilize as a priority to improve its performance regarding innovation as well as export. This article aims to identify the common spaces between innovation and export in terms of current practices within SMEs. Initially, the innovation and export practices were identified in the literature and through a set of interviews with business managers. Then an analysis of similarity put forward the common practices between the innovation and export processes. A data spatialization shows that the common practices concern at least: (1) network management, (2) consideration of the customer, (3) the acquisition of information, (4) skills management, (5) the capitalization of knowledge, (6) the global strategy, (7) the follow-up of the projects, (8) the intellectual property, and finally (9) the corporate culture.
\end{abstract}

Keywords: Export; Innovation; SME; capabilities; common space; data spatialization

Submitted: March 24 $2016 /$ Approved: June 7th 20162016

\section{Introduction}

Globalization changed the rules of the game regarding competitiveness for small-sized companies. Export was identified as one of the main drivers of economic growth (Pla-Barber and Alegre, 2007). According to a study by BPI France (French bank of public investment), innovative SMEs are the most present on foreign markets (PME 2011 - Rapport sur lévolution des PME, 2011). This observation puts forward the existence of a close relationship between innovation and export. Indeed, the study of the link between innovation and export in the context of SMEs represents a very important research area in the current scientific literature (Love and Roper, 2015). More precisely, numerous research works are interested in the direction of causality concerning the impact of the one on the other. This paradigm is supported by two theories: self-selection (Boso et al., 2013; Monreal-Pérez et al., 2012; Raymond and St-Pierre, 2013) and learning-by-exporting (Golovko and Valentini, 2014; Kafouros et al., 2008). These theories demonstrate respectively that innovation has a positive impact on export and vice versa. The theory mainly accepted seems to be self-selection, according to which the innovation can be considered as a necessary but not sufficient condition for export. However, this approach is debatable, mainly because there is no real consensus on the direction of this causality. Indeed, although the theory of self-selection seems to predominate, it coexists with the learning-by-exporting theory and findings are inconsistent from one study to another. On the other hand, certain studies put forward a bidirectional relation through which there seems to be a mutual strengthening of export and innovation, but this strengthening takes a different form according to the direction of the causality considered. The impact of innovation on export is not an exact mirror of the impact of export on innovation (Filipescu et al., 2013). So, the link between innovation and export does not seem to limit itself to a simple cause-and-effect relationship. This study suggests envisaging the relation between innovation and export through an original point of view. Instead of considering innovation as a requirement or a necessary condition for export, this study suggests considering innovation and export as two complementary activities integrating a common space. This common space can be considered as an interface between these two activities, representing the capabilities that an SME has to mobilize primarily in order to create value simultaneously in terms of innovation and export. The development of these capabilities allows the mobilization of joint resources, joint skills and joint knowledge and thus makes it possible to minimize the necessary effort for the improvement of SMEs' performance by acting on two levers at the same time. This makes sense in the context of SMEs, for which the resources are limited.

The objective of this study is therefore to identify the joint capabilities composing this innovation/export common space. The presence or absence of these capabilities within SMEs directly reflects their global capability to innovate and to export. To begin, the appropriate capabilities were identified in the literature, in terms of innovation and export respectively. They were then validated through a series of interviews with business managers and experts in the domain. Then, a similarity analysis highlighted the joint capabilities between innovation and export. However, the results of the similarity analysis were difficult to exploit because they represented a large amount of data. In order to avoid this difficulty, a data spatialization was then realized so as to represent visually the existing similarities between the joint capabilities which were identified. This analysis has led to the characterization of a common space between innovation and export, composed of several dimensions including capabilities associated with both activities.

(1) Université de Lorraine, ERPI (Equipe de Recherche sur les Processus Innovatifs), France.

(2) Université de Lorraine, CEREFIGE (Centre Européen de Recherche en Economie Financière et Gestion d'Entreprise), France.

*Corresponding author: manon.enjolras@univ-lorraine.fr 


\section{Literature review}

This literature review concerns two main dimensions: first, an overview of the studies concerning the link between innovation and export, and the theories on which they rely; second, an analysis of the literature of data visualization. Thus, in a first section, the correlation between innovation and export will be approached with the aim of validating the chosen scientific positioning. Then, the characteristics and the contributions of data visualization will be put forward in order to validate this methodological choice.

\section{The correlation between innovation and export: a causal relationship?}

Numerous publications concern the study of the correlation between innovation and export. This literature review was conducted on more than a hundred scientific publications, mainly stemming from the management sciences.

Few documents concern SMEs in particular but some make comparisons between SMEs and large companies. Certain authors validate the self-selection theory, according to which innovation has a positive impact on the international performances of companies. Others support the learning-by-exporting theory, which considers that the knowledge and the acquired experiences on the international markets improve the innovation capability of companies. And finally, certain studies consider that innovation and export have a mutual positive impact, in the form of virtuous circle. The empirical validation of these theories is mainly made by the analysis of data of existing inquiries (Spanish Business Strategy Survey SBSS; Product Development Survey, PDS) (Love and Roper, 2001)).

\section{Self-selection: the dominant theory}

In a general way, most of the reviewed publications concern the self-selection theory. Innovation confers a competitive advantage on the company, which allows it to acquire a more important general performance and to improve its resources. It allows the company to be more competitive on foreign markets and facilitates its internationalization. Innovation is thus a necessary condition for export (Fig. 1).

Pla Barber and Alègre (2007) validate this theory, through a study of 120 French companies of any size, stemming from the biotechnological sector. In the same way, Roper and Love (2002) also studied the impact of innovation on the international performance of German and English companies. The main finding is that the nature of the impact of innovation on export depends on the context of the company (country of origin, size, and business sector). These findings are confirmed by Altomonte et al. (2013). It is, however, important to underline that in its two studies, innovation is only considered from the perspective of product innovation.
Van Beveren and Vandenbussche (2010) highlight the importance of the correlation between product innovation and process innovation. The launching of a new product or process in an isolated way does not considerably encourage exportation, but the introduction of both simultaneously has a stronger positive impact (Becker and Egger, 2013). This way, companies prepare their arrival on foreign markets by reducing costs (process innovation) and by increasing the quality of the products (product innovation).

Concerning the innovation type (product or process innovation ${ }^{1}$ ), the results of Caldera (2010) show that, in general, innovation fosters export in companies but that process innovations have a less important impact than product innovations. This result is explained by the fact that product innovation allows strong differentiation from competitors on foreign markets as well as higher quality of products, which provides a bigger competitive advantage compared to process innovation, the objective of which is rather to reduce costs.

Concerning SMEs in particular, the innovation / export link is also validated by diverse articles (Cassiman et al., 2010; Cassiman and Golovko, 2011; Higón and Driffield, 2011) within the framework of product innovation. Le Roy and Torres (2001) propose an additional element, by proving that the positive impact of product innovation on the international activities of SMEs does not depend on the geographical area of the target market.

Figure 1. Graphical representation of the self-selection theory

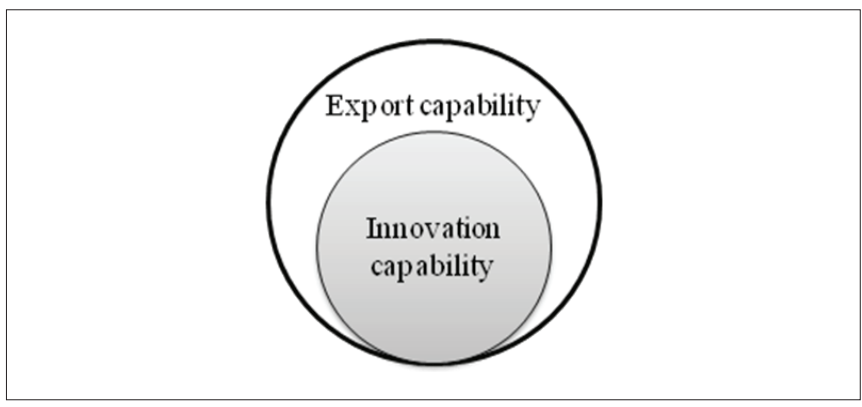

The self-selection theory thus seems mainly accepted in the literature. However, certain studies tend to qualify this paradigm.

Bellone and Guillou (2013) analyze the innovation / productivity / export link. The main result is that innovation is not the only cause of productivity gain and export. Other factors are to be taken into account. On the other hand, Deng et al.(2014) consider that the link between innovation and export can be negative and that it is necessary to take into account the heterogeneity between companies. They demonstrate that, for the Chinese industrial companies, the innovation has a positive impact on the intensity of export, but its impact is not necessarily positive for the survival on foreign markets. Finally, Oura et al. (2015)international experience and export 
performance of SMEs in Brazil»,»container-title»:»International Business Review»,»source»:»ScienceDirect»,»abstract»:»Innovation capacity and international experience are factors often related to the internationalisation process of firms, with export activities as the first stage of the process. However, firms from emerging countries seem to show advantages and follow patterns of international expansion that may differ from firms based in developed countries, where the internationalisation models were created. Specifically, exporting firms from emerging countries tend to have limited resources, especially small firms (e.g., for investing in R\&amp;D also test the impact of innovation capability on the export performance of Brazilian SMEs. However, they advance that innovation capability is mainly considered as an essential factor to improve the performance of companies on foreign markets, but little attention is paid to international experience as a factor equally as important as innovation capability. They prove that international experience has a greater impact on export performance than innovation capability. Thus, the self-selection theory is counterbalanced by another theory, "learning-by-exporting."

The learning-by-exporting theory: exploitation of the experience acquired on foreign markets.

The "learning-by-exporting" theory relies on the hypothesis according to which export allows the improvement of innovation within a company. The discovery of a foreign market allows the company to acquire a large amount of information and knowledge. The acquired knowledge urges the company to adapt itself and thus to innovate to be successful on this new market (Fig. 2). Lileeva and Trefler (2010) adopt this point of view. Their findings indicate that within Canadian industrial firms, the access to foreign markets favors innovation and in particular product innovation.

Kafouros et al. (2008) give the main implications of export concerning the innovation capability and the appropriability of innovation. The notion of threshold is approached: Exportation positively influences innovation (and more particularly the return on investment of innovation) only if the international activities of the company reach a certain threshold (degree of internationalization: DOI (Kotabe et al., 2002)).

Finally, Golovko and Valentini (2014) make a comparison between SMEs and large companies concerning learning-by-exporting. Large companies are more able to develop process innovations subsequent to their entrance on foreign markets (two years later approximately) while SMEs instead develop product innovations one year before their entrance on foreign markets, even more so during the year of their entrance and until two years later. In the same way, Salomon and Shaver (2005) are interested in the time after which export has a positive effect on patent application or on product innovation through the study of Spanish industrial companies. So, export has a positive effect on product innovation approximately two years after the beginning of the company's international activities. A notion of time and of type of innovation thus appears and the results vary according to the size of the company.
Figure 2. Graphical representation of the learning-by-exporting theory

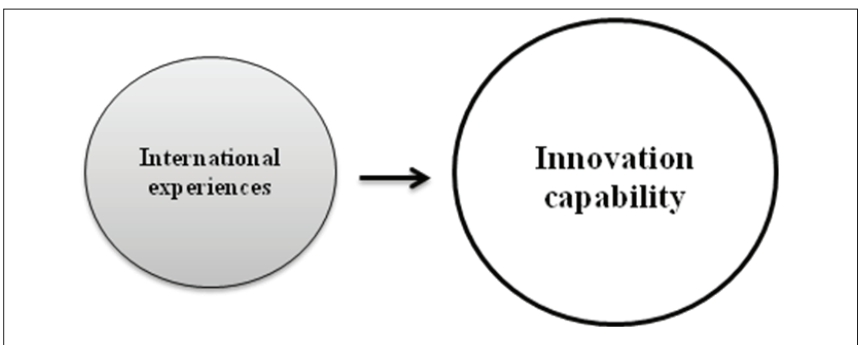

The self-selection theory is therefore questioned by learning-by-exporting. However, despite the fact that these two theories describe an opposite direction of impact, they are not incompatible. A bidirectional innovation / export relation even seems possible.

\section{The virtuous circle theory: a bidirectional impact}

By going farther, Monreal-Perez et al. (2012) study the bidirectional link between innovation and export within Spanish industrial companies. They simultaneously test both hypotheses of self-selection and learning-by-exporting so as to verify whether the innovation / export correlation takes the form of a virtuous circle (Fig. 3). Their results show that the exporters develop more innovation activities and invest more in R\&D. They develop and accumulate more product innovations. According to them, innovation has a positive impact on export. On the other hand, the learning-by-exporting hypothesis is not validated. An explanation: the geographical and cultural distance, which favors learning-by-exporting, does not intervene much in this study because Spain largely exports to EU countries that are culturally close.

In the same way, Damijan et al. (2010) propose an empirical test of the bidirectional innovation / export relation in Slovenia. The results confirm that export encourages process innovation but the other hypotheses are not significant enough to be verified. The results seem valid only for medium and large companies. The theory of the virtuous circle is thus not validated in the conditions of this study. However, Damijan and Kostevc (2010) propose another study in which they study the "learning-by-trade" theory within the Spanish companies (by including importation AND exportation, and not only exportation). This study led to the proposal of a sequence: import / innovation / export / innovation (1) or export / innovation / import / innovation (2). The sequence (1) was retained because the empirical results seem more significant. Import urges companies to innovate (product and process innovations but mainly product innovation) and to begin to export. Finally, export is introduced by innovation and ultimately urges companies to launch new products, but not necessarily new processes. This finding is also verified for small companies.

Finally, Filipescu et al. (2013) propose a study which concerns the reciprocity between export and innovation in the Spanish context. Export is measured according to two categories: the scope of the export activity and its intensity. Innovation is represented by product and process innovation and by the intensity of $\mathrm{R} \& \mathrm{D}$. The main conclusion 
is that the impact of innovation on export is not an exact mirror of the impact of export on innovation. There is a mutual strengthening of export and innovation (Filatotchev and Piesse, 2009) but this strengthening takes a different form according to the direction considered. This study gives an interesting point of view concerning the impact of one activity on the other. It puts forward that the link between innovation and export does not seem to limit itself to a simple cause-andeffect relationship.

Regarding SME in particular, Halilem et al. (2014) propose a study of industrial Canadian SMEs and empirically validate the bidirectional link between innovation and internationalization. This study considers product and process innovation as well as import and export.

Figure 3. Graphical representation of the virtuous circle theory

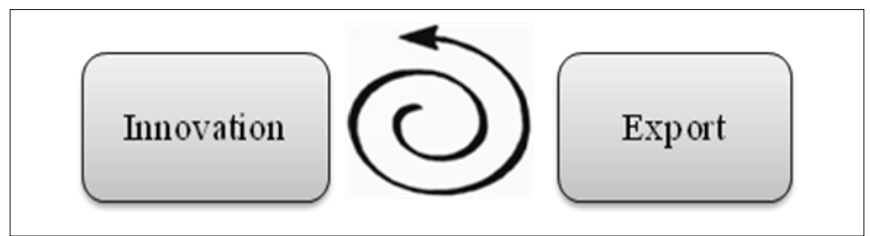

In the same context, Golovko and Valentini (2011) propose a study with a slightly different objective. Instead of studying the impact of one activity on the other, these authors try to show that innovation and export are complementary: if a commitment is made in one of the activities, it facilitates the commitment in the other one (by reducing costs or by increasing profits). The findings show that Spanish manufacturing SMEs that invest in innovation and in export at the same time have better growth than those who invest either in innovation or in export or in neither. Moreover, the return on investment of an activity increases with the performance level of the other activity. This study is interested in the innovation / export link in terms of complementarity and not in terms of impact.

\section{Scientific positioning: a relationship based on complementarity}

In summary, there is no real consensus concerning the link between innovation and export. The majority of the studies consider this link in terms of the impact of innovation on export (self-selection). However, the direction of the impact also takes other forms: the learningby-exporting theory or the virtuous circle (bidirectional relation). In a general way, and whatever the direction, this impact seems more or less strong according to the business sector, the size, the country of origin ... For SMEs it would seem that product innovations are very widely prevalent. They appear before their entrance on the market (self-selection) but also later and in a more important way (learningby-exporting). Thus, the notion of temporality also seems essential. So, when we consider the innovation/export link in terms of impact, it is difficult to reach a consensus. This literature review proves that, in the context of SMEs, innovation cannot be considered as a simple necessary condition for export. In the same way, export cannot limit itself to a prerequisite for innovation.
Figure 4. Scientific positioning of this study

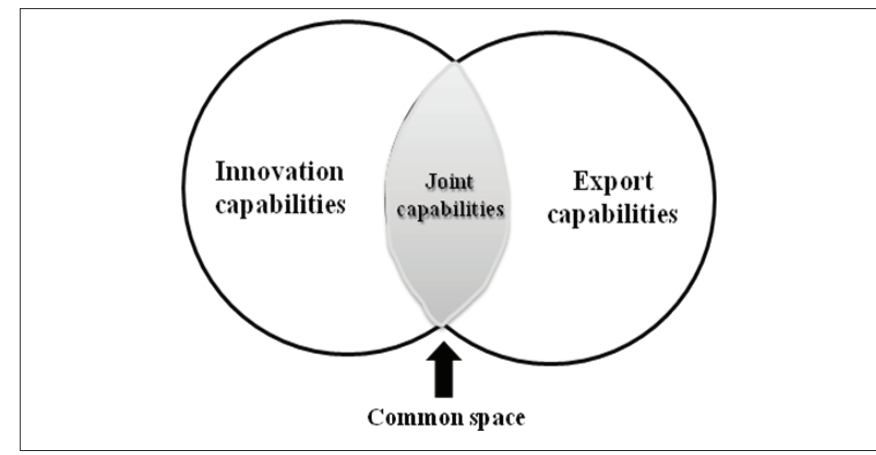

This study thus aims to consider innovation and export as two complementary activities. The coupling of both creates a common intersection (Fig. 4). This intersection includes joint capabilities (activities, resources, skills) common to innovation and to export. An SME has to mobilize these joint capabilities primarily in order to decrease the necessary energy to progress simultaneously in terms of innovation and export. This intersection represents a space common to the innovation and export capabilities, which must be characterized.

\section{Data spatialization}

According to William S. Cleveland (1993), visualization is an essential aspect of data analysis. It reveals the complex structure of data which could be understood in no other way. It allows the discovery of unexpected results and makes it possible to question the expected conclusions.

So, visualization appears as one of the best ways to explore and to try to understand a large quantity of data. It is a visual summary of statistical data that easily provides a general trend. It is, however, necessary to keep in mind that a graphical representation remains, in essence, a simplification of the reality. The multiple parameters of a graphical representation are so many factors which can, deliberately or not, lead to a distortion of reality. It is therefore important to use appropriate tools and methods in order to obtain the representation closest to reality (Yau, 2012).

So, Rodrigues et al. (2006) propose a taxonomic model of the main components of data visualization methodologies. They consider that elements to be taken into account are: the shape, the color, and the position. In other words, it is necessary for data visualization methodologies to allow a visual stimulation (shape / color) and a spatialization of the data (position). However, the color and shape are elements which are sometimes difficult to make clearly interpretable. The positioning has a much more important impact (Skupin and Fabrikant, 2003). Interpreted in the broad sense, data spatialization implies transforming something which is not spatial into something which is spatial. The result is a geometrical representation in a smalldimension space, generally in two or three dimensions, which is intended to make it possible to detect trends and relations which are invisible in a large-dimension database. 
The several spatialization methodologies can be described as follow (Rodrigues et al., 2006):

- Patterned: This is the simplest methodology of spatialization. It consists of associating certain aspects of the considered data with visual properties of geometrical forms (for example, bar charts, pie charts...).

- Projection: Projection corresponds to a display of the data through the representation of functional variables. In other words, the position of an element of data is defined by a known or implicit mathematical function. Principal Component Analysis (PCA) is an example of spatialization by projection.

- Reproduction: The positioning of data comes from an observed phenomenon. This type of spatialization aims to connect the considered data with the physical world. For example, a geographical spatialization through maps is an example of reproduction.

- Structure exposition: This type of spatialization concerns networks and data showing a hierarchical structure. Tools such as mind maps, trees, or force-directed layout can be used.

The types of data spatialization methods are numerous and they must be used according to the available data, the possible correlations existing between these data and the expected results. It is important to select the appropriate data spatialization methodology so as to be able to exploit the data in the most relevant way possible. For this study, the objective is to characterize a common space between innovation and export capabilities. This analysis aims to visualize similarities, so a structure exposition seems to be a suitable spatialization methodology.

\section{Objective and methodology}

\section{Objective of the study}

The objective of this study is to characterize the common space between the innovation and export capabilities of SMEs. SMEs generally have difficulty mobilizing the necessary resources for the development of innovations, as well as for their success on the international markets (Etemad, 2004). The highlighting of capabilities that are common to these two activities allows the identification of high-priority methods of improvement for companies, requiring reduced effort in terms of resources and time. For this study, capability is defined as the ability of an SME to lead a certain activity in touch with innovation and/or export.

It is thus necessary to identify what the capabilities are within SMEs specific to innovation and to export respectively. Once these capabilities have been reviewed, it is necessary to compare them and to identify which one can be considered as common to both activities. These joint capabilities represent the common space between capabilities of innovation and capabilities of export, which will be visualized through a spatialization of the collected data.

\section{Theoretical framework: The potential Innovation Index (PII)}

In recent years, several studies were conducted in regard to the management processes of innovation in companies. Indeed, a large number of researchers tried to define indicators to estimate the innovation capabilities in companies (Adams et al., 2006). The measures of innovation capabilities have evolved by defining two major principles. Firstly, indicators have to measure the internal processes of companies related to innovation in order to understand how companies use the mobilized resources to improve their results. It is necessary to be interested in the practices of companies. Secondly, innovation depends on multiple dimensions. Indicators must therefore be structured on the basis of a multicriteria approach involving various sub-processes (Chiesa et al., 1996). In view of these two major principles, this study leans on the theoretical framework of the Potential Innovation Index (PII), developed by the Research Team on Innovative Processes (ERPI) in France. The PII appears as a relevant indicator for our study because it was tested and validated both theoretically (Boly, 2004; Boly et al., 2014; Rejeb et al., 2008) and empirically on French, Argentine and Chilean SMEs (Galvez et al., 2013; Sepulveda et al., 2010).

It relies on the six most important dimensions mentioned in the literature regarding innovation (Fig. 5): creativity, new product design, human resources management, strategy, project management and knowledge management (Corona, 2005).

Figure 5. The 6 dimensions of the Potential Innovation Index

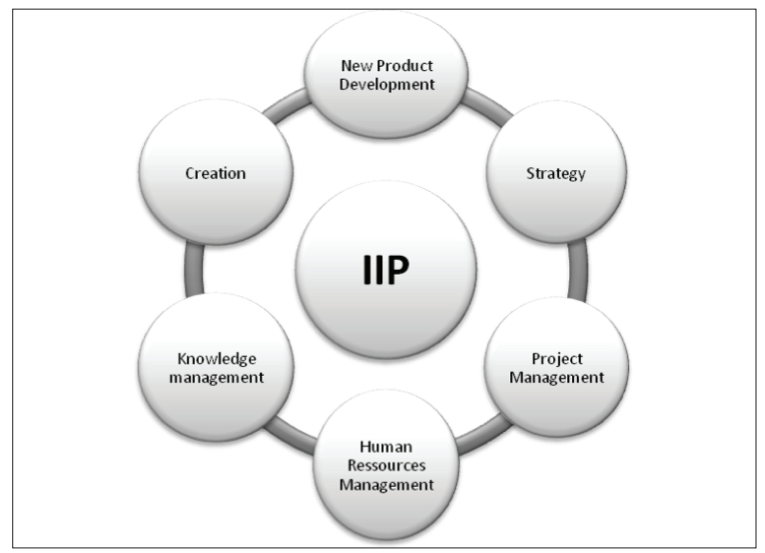

Each of these dimensions includes several capabilities, which themselves include a number of observable phenomena (Fig. 6). An observable phenomenon may be defined as a routine activity within the company, requiring allocation of resources (time, money, and personnel) and producing a tangible and verifiable result. The observable phenomena thus play the role of indicators allowing the estimation of the considered capability. If these observable phenomena are present within the company, the capability which they characterize can be considered as good. 
Figure 6. Structure of the Potential Innovation Index

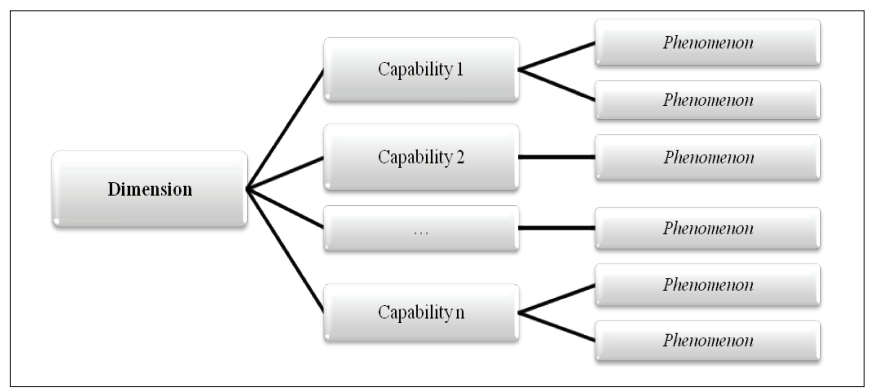

\section{Approach}

As explained previously, this study relies on the PII methodology. This index provides a solid theoretical framework concerning the capabilities that are specific to innovation. Relying on this theoretical basis, this study took place in five phases:

- The first phase consisted of identifying dimensions and capabilities related to export within the scientific literature.

- The collected data were then structured according to the same model as the PII: dimensions / capabilities / observable phenomena (Fig. 5 and 6).
- Then, the identified data were validated within international SMEs and with experts of exportation (researchers, consultants, business advisors).

- Then, a similarity analysis was conducted at the level of the innovation and export capabilities so as to identify those who could be considered as common.

- Finally, a methodology of data spatialization was used so as to obtain an exploitable representation of the data with the aim of better visualizing the results obtained.

\section{Results}

Identification of the export best practices.

The first phase of this study consisted of reviewing dimensions and capabilities related to export within the scientific literature. This bibliographical research was conducted on about fifty scientific articles. After a descriptive analysis of these publications and the structuring of the collected data, eight dimensions concerning export were put forward and characterized in the form of capabilities and observable phenomena (Tab. 1).

Table 1. Theoretical dimensions and capabilities

\begin{tabular}{|c|c|c|}
\hline Dimensions & Publications mentioning this dimension & Related capabilities \\
\hline \multirow{2}{*}{ Information, knowledge management } & \multirow{2}{*}{33} & Information and knowledge acquisition \\
\hline & & Capitalization and sharing \\
\hline \multirow{3}{*}{ Internal skills management } & \multirow{3}{*}{9} & Language skills \\
\hline & & Technical and business skills \\
\hline & & Administrative skills \\
\hline Cultural and human aspects management & 22 & International culture of the company / manager profile \\
\hline \multirow{6}{*}{ Mobilization of external skills } & \multirow{6}{*}{18} & Communication / translation \\
\hline & & Research of support and funding \\
\hline & & Payments / international trade / insurance \\
\hline & & Legislation / Standards \\
\hline & & Transport and customs duties \\
\hline & & Partnerships \\
\hline \multirow{3}{*}{ Strategy } & \multirow{3}{*}{19} & Formalization of the international strategy \\
\hline & & Intellectual property \\
\hline & & Identification and mobilization of dedicated resources \\
\hline \multirow{3}{*}{ Project management } & \multirow{3}{*}{5} & Management of the project process \\
\hline & & Selection / prioritization of the projects \\
\hline & & Organization / allocation of responsibilities \\
\hline \multirow{4}{*}{ Supply chain management } & \multirow{4}{*}{12} & Supplier management \\
\hline & & Production management \\
\hline & & Transport \\
\hline & & Distribution strategy \\
\hline \multirow{3}{*}{ Communication / marketing } & \multirow{3}{*}{7} & Adaptation of the product \\
\hline & & Marketing mix \\
\hline & & Customer relationship \\
\hline
\end{tabular}


Then, several interviews (Tab. 2) were conducted with managers of international SMEs, as well as with experts in the internationalization of SMEs (researchers, consultants, advisors...). These interviews made it possible to validate the theoretical data identified in the literature so as to obtain as realistic a model as possible. Eight theoretical dimensions were validated and these interviews in particular made it possible to complete and to specify capabilities and associated observable phenomena.

Table 2. Description of the interviews

\begin{tabular}{|c|c|}
\hline Interview & Contact person \\
\hline 1 & Exporting SME (medium-high technology ${ }^{1}$ ) \\
\hline 2 & Exporting SME (medium-high technology ${ }^{1}$ ) \\
\hline 3 & Exporting SME (low-medium technology ${ }^{1}$ ) \\
\hline 4 & Exporting SME (medium-high technology ${ }^{1}$ ) \\
\hline 5 & Exporting SME (medium-high technology ${ }^{1}$ ) \\
\hline 6 & Exporting SME (medium-high technology ${ }^{1}$ ) \\
\hline 7 & Exporting SME (low technology ${ }^{1}$ ) \\
\hline 8 & Exporting SME (medium-high technology ${ }^{1}$ ) \\
\hline 9 & Exporting SME (medium-high technology ${ }^{1}$ ) \\
\hline 10 & Business Advisor (private sector) \\
\hline 11 & Business Advisor (public sector) \\
\hline 12 & Researcher \\
\hline 13 & Researcher \\
\hline 14 & Researcher \\
\hline 15 & Business Advisor (public sector) \\
\hline 16 & Researcher \\
\hline 17 & Business Advisor (public sector) \\
\hline 18 & Business Advisor (public sector) \\
\hline 19 & Business Advisor (private sector) \\
\hline
\end{tabular}

${ }^{1}$ According to the classification by technological level, source: Hatzichronoglou (1997)

\section{Identification of the common space between innovation and export}

The following phase of this study concerned the identification of the common space between innovation and export capabilities. The previous phases provide a frame of reference that includes dimensions, capabilities and specific observable phenomena associated with the activities of innovation and export respectively (Tab. 3). This frame of reference arises from the scientific literature, but it was also validated empirically for innovation as well as for export. 
Table 3. Reference framework: dimensions / capabilities

\begin{tabular}{|c|c|c|c|c|c|}
\hline \multicolumn{3}{|c|}{ INNOVATION } & \multicolumn{3}{|c|}{ EXPORT } \\
\hline Dimension & Related capabilities & Code & Dimension & Related capabilities & Code \\
\hline \multirow[t]{2}{*}{ Creativity } & \multirow{2}{*}{$\begin{array}{l}\text { Use of tools to assist creativity } \\
\text { Integration of customers and suppliers during } \\
\text { the design process } \\
\text { Organization, gathering and management of the } \\
\text { external information }\end{array}$} & I1 & $\begin{array}{l}\text { Information, } \\
\text { knowledge } \\
\text { management }\end{array}$ & $\begin{array}{l}\text { Information and knowledge acquisition } \\
\text { Capitalization and sharing }\end{array}$ & E1 \\
\hline & & 13 & \multirow[b]{2}{*}{$\begin{array}{l}\text { Internal sldills } \\
\text { management }\end{array}$} & Language skills & E3 \\
\hline \multirow{2}{*}{$\begin{array}{l}\text { New product } \\
\text { design }\end{array}$} & $\begin{array}{l}\text { Use of design-support tools } \\
\text { Existence of design-support methodologies }\end{array}$ & I4 & & $\begin{array}{l}\text { Technical and business skills } \\
\text { Administrative skills }\end{array}$ & $\begin{array}{l}\text { E4 } \\
\text { E5 }\end{array}$ \\
\hline & Information and communication technologies & I6 & $\begin{array}{r}\text { Cultural and human } \\
\text { aspects management }\end{array}$ & International culture of the company & E6 $(/ \mathrm{E} 7)^{1}$ \\
\hline \multirow{3}{*}{ Strategy } & $\begin{array}{l}\text { Integrated strategy to favor innovation } \\
\text { Network operation }\end{array}$ & $\begin{array}{l}\text { I7 } \\
\text { I8 }\end{array}$ & \multirow{6}{*}{$\begin{array}{l}\text { Mobilization of } \\
\text { external skills }\end{array}$} & & $\mathrm{E} 8$ \\
\hline & Customer importance & I9 & & Research of support and funding & E9 \\
\hline & Funding & I10 & & Payments/ insurance & E10 \\
\hline \multirow{2}{*}{$\begin{array}{l}\text { Human resources } \\
\text { management }\end{array}$} & $\begin{array}{l}\text { Management of the company's skills and know- } \\
\text { how }\end{array}$ & I11 & & Legislation / Standards & E11 \\
\hline & Innovation stimulation & I12 & & Transport and customs duties & E12 \\
\hline \multirow{3}{*}{$\begin{array}{c}\text { Project } \\
\text { management }\end{array}$} & Project management & I13 & & Partnerships & E13 \\
\hline & Project portfolio management & I14 & \multirow{3}{*}{ Strategy } & Formalization of the international strategy & E14 \\
\hline & Organization of the tasks related to innovation & I15 & & Intellectual property & E15 \\
\hline \multirow[b]{2}{*}{$\begin{array}{l}\text { Knowledge } \\
\text { management }\end{array}$} & $\begin{array}{l}\text { Continuous improvement of the innovation } \\
\text { process }\end{array}$ & I16 & & $\begin{array}{l}\text { Identification and mobilization of dedicated } \\
\text { resources }\end{array}$ & E16 \\
\hline & $\begin{array}{l}\text { Intellectual property management } \\
\text { Knowledge capitalization }\end{array}$ & $\begin{array}{l}\mathrm{I} 17 \\
\mathrm{I} 18\end{array}$ & \multirow[t]{2}{*}{$\begin{array}{c}\text { Project } \\
\text { management }\end{array}$} & $\begin{array}{l}\text { Management of the project process } \\
\text { Selection / prioritization of the projects }\end{array}$ & $\begin{array}{l}\text { E17 } \\
\text { E18 }\end{array}$ \\
\hline & & & & Organization / allocation of responsibilities & E19 \\
\hline & & & $\begin{array}{l}\text { Supply chain } \\
\text { management }\end{array}$ & $\begin{array}{l}\text { Supplier management } \\
\text { Production management } \\
\text { Transport } \\
\text { Distribution strategy }\end{array}$ & $\begin{array}{l}\mathrm{E} 20 \\
\mathrm{E} 21 \\
\mathrm{E} 22 \\
\mathrm{E} 23\end{array}$ \\
\hline & & & $\begin{array}{l}\text { Communication / } \\
\text { Marketing }\end{array}$ & $\begin{array}{l}\text { Adaptation of the product } \\
\text { Marketing mix } \\
\text { Customer relationship }\end{array}$ & $\begin{array}{l}\text { E24 } \\
\text { E25 } \\
\text { E26 }\end{array}$ \\
\hline
\end{tabular}

Sources: Galvez et al. (2013) and our study

(2) The bibliographic analysis, as well as the data collected during the interviews with experts in export highlighted the difficulty of identifying observable phenomena for capacity E6 (/E7). The initiation of an export process impacts the company in its entirety. When a company deals with foreign customers / partners, the cultural aspects must be managed on a day-to-day basis. The manager has to be a driver of this initiative but he also has to see to it that a real international culture is broadcast within the company. So this capability concerns several aspects: the culture of the company (E6) and the personality of the manager (E7). This last aspect contains a human dimension, and it is difficult to estimate the personality of a manager in the form of verifiable and quantifiable indicators. That is why E7 is not a part of the retained capabilities for this analysis, despite the fact that the manager profile remains an extremely important point to take into account, especially in the context of SMEs. However, the corporate culture (E6) is considered as a capability of export for this study. 
In order to identify a common space within this framework, a similarity analysis was conducted (Degenne and Vergès, 1973). The objective of this analysis was to identify similar capabilities by comparing pairwise the innovation capabilities and the export capabilities. For greater accuracy, the comparison was made at the level of observable phenomena (Fig. 7), so as to create a similarity matrix (Fig. 8).

Figure 7. Principle of the similarity analysis

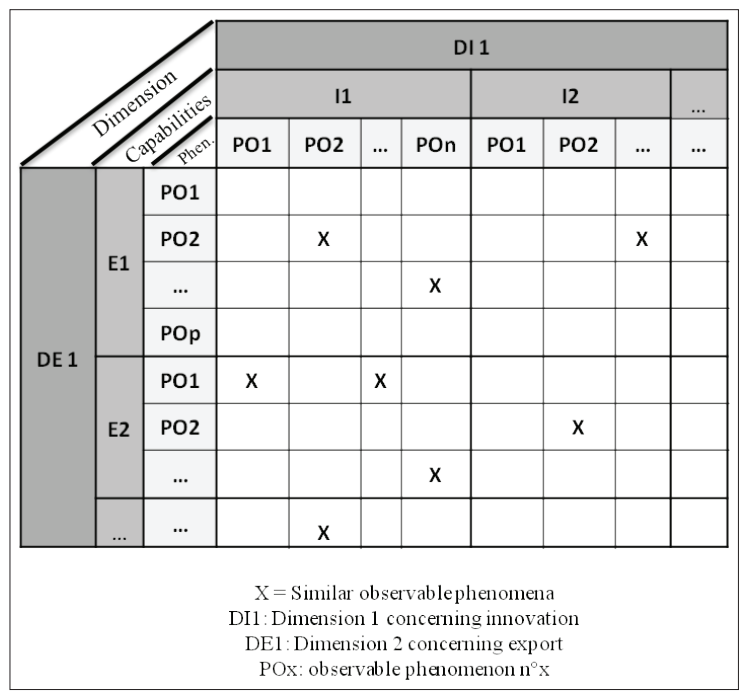

The objective is to identify the number of common observable phenomena for each pair of capabilities. This number of common observable phenomena makes it possible to calculate a similarity degree. Equation 1 shows the definition of this similarity degree: $I$ represents an innovation capability including $n$ observable phenomena, and $E$ represents an export capability including $p$ observable phenomena. When $I$ and $E$ are compared, the number of common observable phenomena $k$ between $p$ and $n$ makes it possible to calculate the similarity degree $D$ between $I$ and $E$.

$$
D_{I, E}=\frac{k}{(p+n)}
$$

(Equation 1)

This analysis extends to the matrix represented by Figure 8 .

For the continuation of the study, it was decided to consider only the similarities with a degree greater than 0.25 , the lower similarities being less representative.
Figure 8. Similarity matrix

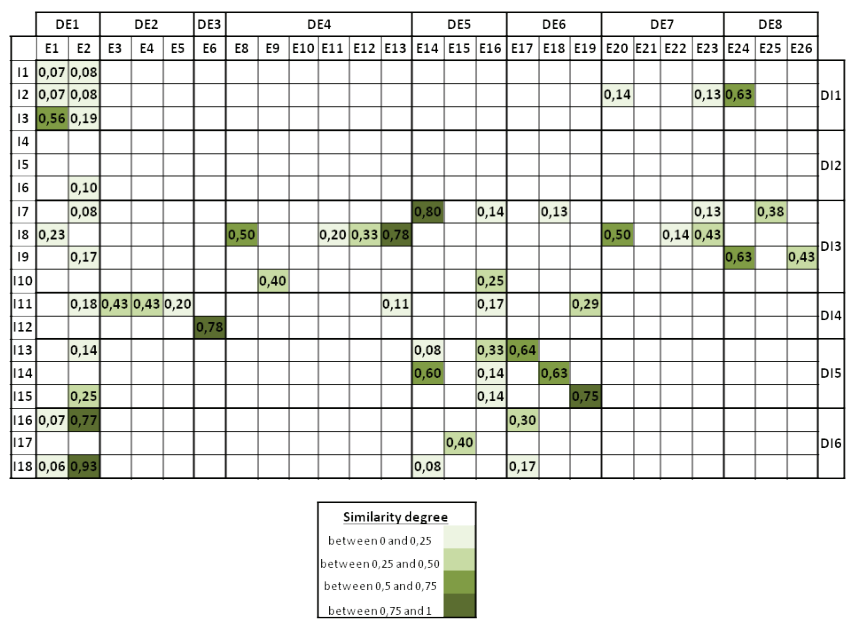

Data spatialization by using force-based algorithms

The similarity matrix (Fig. 8) gives an indication of the capacities which can be considered as similar, though its interpretation remains difficult. Indeed, this matrix puts forward pairs of capacities having a more or less strong degree of similarity and this degree of similarity is important to take into account for this study. However, this representation does not enable the identification of clusters taking into account existing links between the data and strength of these links. But this visualization is necessary for the definition of a common space between the SMEs' innovation and export capabilities. Therefore, the decision was made to realize a "structuring" data spatialization through the Gephi software, so as to highlight the links between the considered data.

Within the "structuring" data spatialization methodologies, numerous algorithms can be used. Some algorithms allow a geographical representation of the data, some aim at classifying data, and others have the objective to put forward divisions or complementarities. This is the case with the force-based algorithms. This study aims at identifying which activities are common to innovation and export, by studying the similarity between the observable phenomena of each of them. The use of a force-based algorithm seems completely suitable. The principle of these algorithms is the following: every datum is represented by a node (every capability of innovation and export is represented by a node). All the nodes repel each other, respecting the principle of magnets. The more the nodes are dispersed, the less they repel each other. The links can be considered as springs between two nodes (the stronger the weight of the link, the stiffer the spring). At every step of the algorithm, the sum of the forces is applied to every node. These nodes move until they reach a stable state. The force-based algorithms position nodes with regard to the others. Graphs still do not converge on the same final configuration. So it is not possible to read the position of a node as such, and it is necessary to compare its position with the others. 
The Gephi software proposes several force-based algorithms, so it was necessary to choose the algorithm most suited to this study. Table 4 proposes a comparison of these various algorithms.

Table 4. Overview of the force-based algorithms available on Gephi software, inspired by Jacomy et al. (2014)

\begin{tabular}{c|c|c|c}
\hline $\begin{array}{c}\text { Fruchterman et } \\
\text { Rheingold }\end{array}$ & Yifan Hu & OpenOrd & $\begin{array}{c}\text { ForceAtlas / } \\
\text { ForceAtlas 2 }\end{array}$ \\
\hline $\begin{array}{c}\text { Algorithm } \\
\text { Algorithm high- } \\
\text { plementarities } \\
\text { between data } \\
\text { complighting the } \\
\text { itientar- between } \\
\text { data, rather for } \\
\text { processing large } \\
\text { data sets }\end{array}$ & $\begin{array}{c}\text { Open source } \\
\text { algorithm, } \\
\text { highlighting di- } \\
\text { visions between } \\
\text { data. }\end{array}$ & $\begin{array}{c}\text { Algorithm } \\
\text { highlighting the } \\
\text { complementar- } \\
\text { ities between } \\
\text { data }\end{array}$ \\
\hline
\end{tabular}

This overview puts forward some differences between the considered algorithms. Yifan $\mathrm{Hu}$ is rather intended to handle a significant number of data, which is not the case for this study. This algorithm was thus rejected. On the other hand, OpenOrd puts forward divisions between data. The objective of this study is to highlight similarities. This algorithm was also rejected.

To make a choice between the ForceAtlas and Fruchterman \& Rheingold algorithms, it is necessary to go into detail. These two algorithms are based on an energy model integrating an attraction force and a repulsion force. They rely on a certain formula for the attraction force and a certain formula for the repulsion force respectively, depending on the distance $d$ between two nodes. It is possible to define the energy model ( $\mathrm{a}=$ attraction; $\mathrm{r}=$ repulsion) by considering the exponent allocated to the distance $\mathrm{d}$ in the attraction and repulsion forces formula (Noack, 2007). If ForceAltas2 (version updated by ForceAtlas) and Fruchterman \& Rheingold are compared, their energy models are respectively $(1 ; 1)$ and $(2 ; 1)$. Indeed, the attraction and repulsion forces of the algorithm Fruchterman \& Rheingold are defined according to Equation 2 (Fruchterman and Reingold, 1991). The attraction and repulsion forces of the ForceAltas 2 algorithm are defined according to Equation 3 (Jacomy et al., 2014).

$$
\begin{aligned}
& \left\{\begin{array}{l}
F a_{F \& R}=\frac{d^{2}}{k} \\
F r_{F \& R}=\frac{-k^{2}}{d}
\end{array}\right. \\
& D_{I, E}=\frac{k}{(p+n)}
\end{aligned}
$$

\section{With $C$ and $k$ : constant and d: distance between two nodes}

The calculation of a-r according to the energy model ( $\mathrm{a} ; \mathrm{r}$ ) associated with the algorithm in question makes it possible to obtain an additional indication for the choice of the most appropriate algorithm.
According to Noak (2009), a weak a-r favors the visualization of clusters because it means that the attraction force depends less on the distance $\mathrm{d}$ between two nodes, while the repulsion force depends more on it. The calculation of a-r for the Fruchterman \& Rheingold algorithm is equal to 3 (Equation 4) while that for ForceAtlas 2 is equal to 2 (Equation 5).

$$
\begin{gathered}
a_{F A 2}-r_{F A 2}=1-(-1)=2 \\
a_{F \& R}-r_{F \& R}=2-(-1)=3
\end{gathered}
$$

(Equation 4)

(Equation 5)

So, the ForceAtlas2 algorithm seems more suited to the visualization of clusters, which seems relevant to this study. This algorithm was therefore retained.

The result of the data spatialization is presented in Figure 9. The Gephi software identified nine groups separated by "modularity class." Modularity is often used in the optimization methods to detect the structure of communities within networks. Gephi uses Leuven's modularity calculation method (Blondel et al., 2008). This includes two phases. First of all, the "little" communities are identified by optimizing the modularity in a local way. Secondly, the nodes of the same community are grouped and a new network is built. Within this new network, nodes become communities. These stages are repeated in an iterative way until a maximum of modularity is reached. This process leads to the hierarchical decomposition of the network. The capacities of the same "modularity class" can be considered as a dimension common to both innovation and export activities.

Figure 9. Data Spatialization: clustering of similar capabilities

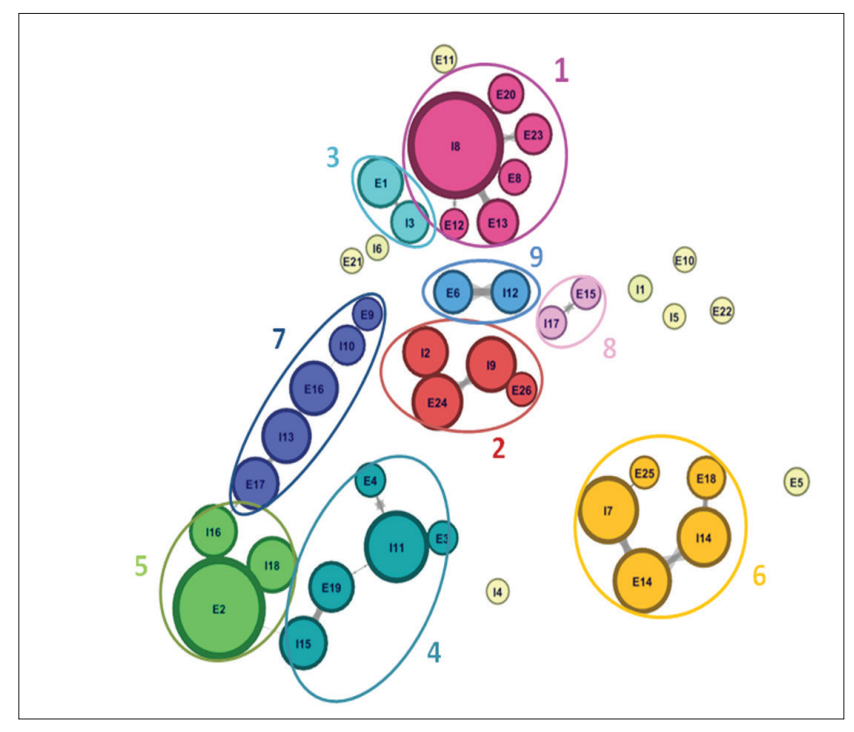

\section{Discussion}

The objective of this study is to identify the common spaces between the capabilities of innovation and the capabilities of export. The similarity analysis relying on the frame of reference describing separately the innovation and export capabilities highlighted the pairs of practices which can be considered as similar, and the intensity of this similarity. 
Then, a structural data spatialization was realized, through the use of a force-based algorithm. This data visualization methodology has in particular the advantage to show each datum only once, which facilitates the interpretation of the results. It also takes into account the strength of the similarity between the data. Through the use of the Gephi software and the ForceAtlas2 algorithm, the findings show clusters of capabilities which can be considered as similar (Tab. 5). These clusters of capabilities represent nine dimensions which are common to both innovation and export activities.

Table 5. Interpretation of the data spatialization results

\begin{tabular}{c|c|c}
\hline Group & Included capabilities $\quad$ (innovation and export) & Description of the common dimension \\
\hline 1 & $\mathrm{E} 20 ; \mathrm{E} 23 ; \mathrm{E} 12 ; \mathrm{E} 13 ; \mathrm{E} 8 ; \mathrm{I} 8$ & Mobilization of external skills \\
\hline 2 & $\mathrm{I} 2 ; \mathrm{I} 9 ; \mathrm{E} 26 ; \mathrm{E} 24$ & Consideration of the customer \\
\hline 3 & $\mathrm{E} 1 ; \mathrm{I} 3$ & Acquisition of information and knowledge \\
\hline 4 & $\mathrm{E} 4 ; \mathrm{E} 3 ; \mathrm{E} 19 ; \mathrm{I} 11 ; \mathrm{I} 15$ & Allocation of human resources and internal skills management \\
\hline 5 & $\mathrm{E} 2 ; \mathrm{I} 16 ; \mathrm{I} 18$ & Capitalization and sharing of knowledge \\
\hline 6 & $\mathrm{I} 7 ; \mathrm{I} 14 ; \mathrm{E} 25 ; \mathrm{E} 18 ; \mathrm{E} 14$ & Definition of a global strategy and prioritization of projects \\
\hline 7 & $\mathrm{E} 17 ; \mathrm{I} 13 ; \mathrm{E} 16 ; \mathrm{I} 10 ; \mathrm{E} 9$ & Allocation of financial resources and follow-up of the projects \\
\hline 8 & $\mathrm{E} 6 ; \mathrm{I} 12$ & Diffusion of the corporate culture \\
\hline 9 & $\mathrm{I} 17 ; \mathrm{E} 15$ & Management and exploitation of intellectual property \\
\hline
\end{tabular}

The common dimensions identified concern the management of internal and external skills (Groups 1 and 4), the acquisition and the capitalization of information (Groups 2 and 5), the management of projects and resources (Group 7), and the strategy (Group 6). Two additional groups appear: the management of intellectual property and the diffusion of the corporate culture (human and cultural aspects). This analysis provides an important degree of precision concerning the characterization of the common space between capacities of innovation and export.

\section{Conclusion}

Through this study, the existence of a common space between the innovation and export capabilities was highlighted. First, a reference frame was created so as to represent separately the innovation and export capabilities of SMEs. Then, a similarity analysis between the innovation capabilities and the export capabilities was realized, with the aim of identifying and characterizing a common space. This common space is composed of capacities common to the activities of innovation and the activities of export. These capacities are grouped into nine common dimensions through the use of a data spatialization methodology: (1) network management, (2) consideration of the customer, (3) the acquisition of information, (4) skills management, (5) the capitalization of knowledge, (6) the global strategy, (7) the follow-up of the projects, (8) the intellectual property, and finally (9) the corporate culture.

Therefore, this research work confirms the scientific positioning according to which innovation and export must be considered as two complementary activities, integrating an interface representing the capabilities which an SME has to mobilize primarily to create simultaneously value in terms of innovation and export. The development of these capabilities allows the mobilization of common resources, common skills and common knowledge and makes it possible to minimize the effort associated with the creation of a virtuous circle of innovation / export, supported by a value-creating common interface. The contributions of this study concern first of all the scientific research, by proposing an original paradigm considering the innovation / export link not in terms of the direction of causality, but rather through an integrative and systemic point of view. The study of the intersection between the capabilities of export and innovation represents a contribution to the literature. On the other hand, this study represents a contribution for the support of SMEs, which generally have difficulty mobilizing the necessary resources for the development of innovations, as well as for their success on the international markets. These results allow the identification of high-priority ways of improvement requiring reduced effort in terms of resources and time. However, this research work shows several limits. Indeed, it was chosen for this study to focus on capabilities. But the common space between innovation and export probably does not limit itself to joint capabilities. The joint capacities identified by this study are defined by the abilities to conduct a certain activity common to innovation and export. However, these joint capabilities are dependent on available resources to carry out these activities. These resources to be mobilized can take various forms: knowledge, available skills, tools, etc. It would be interesting to identify these joint resources. One of these resources is the manager profile, which was already approached in this study. Indeed, the manager profile cannot be characterized in the form of observable phenomena. Thus, it cannot be considered as a capability in the sense of our study, but rather as a joint resource. The human aspects play an extremely important role in innovation activities (Rodriguez and Hechanova, 2014) as well as in export activities (Alaoui and Makrini, 2014). This is especially the case in the context of SMEs, because the manager is generally omnipresent and sometimes the only decision-maker (Child and Hsieh, 2014). The ninth dimension, 
corporate culture, relies on capabilities E6 and I12, and both of these mobilize the manager profile as a joint resource. One of the main perspectives of this work therefore consists of characterizing this joint resource, so as to identify what the ideal profile of an SME manager is through a common innovation / export point of view.

\section{Acknowledgements}

This research work has been cofinanced by the Regional Council of Lorraine (France) and the Research Chair PRINCIP, Granted by the French "Innovation and Industry Fund" (F2I) and the Union of Metal Industries and Professions (UIMM). The authors would also underline that this work is on line with the IDEFI InnovENT-E project (Initiatives of excellence in innovative training) related to the innovation and export capabilities of SMEs.

\section{References}

Adams, R., Bessant, J., Phelps, R., 2006. Innovation management measurement: A review. International Journal of Management Reviews 8, 21-47. doi:10.1111/j.1468-2370.2006.00119.x

Alaoui, A., Makrini, H.E., 2014. Analyse des effets des pratiques managériales sur la performance à l'export. Etude empirique des PME marocaines. Management \& Avenir $\mathrm{N}^{\circ} 72,15-33$.

Altomonte, C., Aquilante, T., Békés, G., Ottaviano, G.P., 2013. Internationalization and innovation of firms: evidence and policy. Economic Policy 28, 663-700.

Becker, S.O., Egger, P.H., 2013. Endogenous product versus process innovation and a firm's propensity to export. Empirical Economics 44, 329-354. doi:10.1007/s00181-009-0322-6

Bellone, F., Guillou, S., 2013. Innovation et primes à l'exportation : une analyse empirique sur données d’entreprises françaises. Economie \& prévision 197-198, 45-61.

Blondel, V.D., Guillaume, J.-L., Lambiotte, R., Lefebvre, E., 2008. Fast unfolding of communities in large networks. Journal of Statistical Mechanics: Theory and Experiment 2008, P10008. doi:10.1088/1742$5468 / 2008 / 10 / \mathrm{P} 10008$

Boly, V., 2004. Ingénierie de linnovation: organisation et méthodologies des entreprises innovantes. Hermès Science Publications : Lavoisier, Paris.

Boly, V., Morel, L., Assielou, N.G., Camargo, M., 2014. Evaluating innovative processes in french firms: Methodological proposition for firm innovation capacity evaluation. Research Policy 43, 608-622. doi:10.1016/j.respol.2013.09.005

Boso, N., Story, V.M., Cadogan, J.W., Micevski, M., Kadić-Maglajlić, S., 2013. Firm Innovativeness and Export Performance: Environmental, Networking, and Structural Contingencies. Journal of International Marketing 21, 62-87. doi:10.1509/jim.13.0052
Caldera, A., 2010. Innovation and exporting: evidence from Spanish manufacturing firms. Review of World Economics 146, 657-689. doi:10.1007/s10290-010-0065-7

Cassiman, B., Golovko, E., 2011. Innovation and internationalization through exports. Journal of International Business Studies 42, 56-75. doi:10.1057/jibs.2010.36

Cassiman, B., Golovko, E., Martínez-Ros, E., 2010. Innovation, exports and productivity. International Journal of Industrial Organization, Selected Papers, European Association for Research in Industrial Economics 36th Annual Conference, Ljubljana, Slovenia, September 3-5, 2009 28, 372-376. doi:10.1016/j.ijindorg.2010.03.005

Chiesa, V., Coughlan, P., Voss, C.A., 1996. Development of a technical innovation audit. Journal of Product Innovation Management 13, 105-136. doi:10.1016/0737-6782(95)00109-3

Child, J., Hsieh, L.H.Y., 2014. Decision mode, information and network attachment in the internationalization of SMEs: A configurational and contingency analysis. Journal of World Business 49, 598610. doi:10.1016/j.jwb.2013.12.012

Cleveland, W.S., 1993. Visualizing Data. Hobart Press.

Corona, J., 2005. Innovation et métrologie: une approche en terme d'indice d'innovation potentielle (Thèse de doctorat). Institut National Polytechnique de Lorraine.

Damijan, J., Kostevc, C., Polanec, S., 2010. From Innovation to Exporting or Vice Versa? The World Economy 33, 374 - 398. doi:10.1111/ j.1467-9701.2010.01260.x

Damijan, J.P., Kostevc, C., 2010. Learning from trade through innovation: Causal link between imports, exports and innovation in Spanish microdata. LICOS - Centre for Institutions and Economic Performance, KU Leuven.

Degenne, A., Vergès, P., 1973. Introduction à l'analyse de similitude. Revue française de sociologie 14, 471-512. doi:10.2307/3320247

Deng, Z., Guo, H., Zhang, W., Wang, C., 2014. Innovation and survival of exporters: A contingency perspective. International Business Review 23, 396-406. doi:10.1016/j.ibusrev.2013.06.003

Etemad, H., 2004. Internationalization of Small and Medium-sized Enterprises: A Grounded Theoretical Framework and an Overview. Canadian Journal of Administrative Sciences 21, 1-21. doi:10.1111/j.1936-4490.2004.tb00319.x

Filatotchev, I., Piesse, J., 2009. R\&D, internationalization and growth of newly listed firms: European evidence. Journal of International Business Studies 40, 1260-1276. doi:10.1057/jibs.2009.18 
Filipescu, D.A., Prashantham, S., Rialp, A., Rialp, J., 2013. Technological Innovation and Exports: Unpacking Their Reciprocal Causality. Journal of International Marketing 21, 23-38. doi:10.1509/jim.12.0099

Fruchterman, T.M.J., Reingold, E.M., 1991. Graph drawing by forcedirected placement. Software: Practice and Experience. 21, 11291164. doi:10.1002/spe.4380211102

Galvez, D., Camargo, M., Rodriguez, J., Morel, L., 2013. PII- Potential Innovation Index: a Tool to Benchmark Innovation Capabilities in International Context. Journal of Technology Management \& Innovation $8,36-45$.

Golovko, E., Valentini, G., 2014. Selective Learning-by-Exporting: Firm Size and Product Versus Process Innovation. Global Strategy Journal 4, 161-180. doi:10.1002/gsj.1080

Golovko, E., Valentini, G., 2011. Exploring the complementarity between innovation and export for SMEs growth. Journal of International Business Studies 42, 362-380.

Halilem, N., Amara, N., Landry, R., 2014. Exploring the relationships between innovation and internationalization of small and medium-sized enterprises: A nonrecursive structural equation model.

Canadian Journal of Administrative Sciences 31, 18-34. doi:10.1002/ cjas. 1272

Hatzichronoglou, T., 1997. Révision des classifications des secteurs et produits de haute technologie, Editions OCDE.

Higón, D.A., Driffield, N., 2011. Exporting and innovation performance: Analysis of the annual Small Business Survey in the UK. International Small Business Journal 29, 4-24. doi: $10.1177 / 0266242610369742$

Jacomy, M., Heymann, S., Venturini, T., Bastian, M., 2014. ForceAtlas2, A graph Layout Algorithm for Handy Network Visualization Design for the Gephi Software. PLoS ONE 9.

Kafouros, M.I., Buckley, P.J., Sharp, J.A., Wang, C., 2008. The role of internationalization in explaining innovation performance. Technovation 28, 63-74. doi:10.1016/j.technovation.2007.07.009

Kotabe, M., Srinivasan, S.S., Aulakh, P.S., 2002. Multinationality and Firm Performance: The Moderating Role of R\&D and Marketing Capabilities. Journal of International Business Studies 33, 79-97.

Le Roy, F., Torrès, O., 2001. La place de l'innovation dans les stratégies concurrentielles des P.M.E. internationales. Innovations 13, 43-60. doi:10.3917/inno.013.0043

Lileeva, A., Trefler, D., 2010. Improved Access to Foreign Markets Raises Plant-level Productivity...For Some Plants. The Quarterly Journal of Economics 125, 1051-1099. doi:10.1162/qjec.2010.125.3.1051
Love, J.H., Roper, S., 2015. SME innovation, exporting and growth: A review of existing evidence. International Small Business Journal 33, 28-48. doi:10.1177/0266242614550190

Love, J.H., Roper, S., 2001. Location and network effects on innovation success: evidence for UK, German and Irish manufacturing plants. Research Policy 30, 643-661. doi:10.1016/S0048-7333(00)00098-6

Monreal-Pérez, J., Aragón-Sánchez, A., Sánchez-Marín, G., 2012. A longitudinal study of the relationship between export activity and innovation in the Spanish firm: The moderating role of productivity. International Business Review 21, 862-877. doi:10.1016/j.ibusrev.2011.09.010

Noack, A., 2009. Modularity clustering is force-directed layout. Physical Review E 79, 026102. doi:10.1103/PhysRevE.79.026102

Noack, A., 2007. Energy Models for Graph Clustering. Journal of Graph Algorithms and Applications 11, 453-480.

Oura, M.M., Zilber, S.N., Lopes, E.L., 2015. Innovation capacity, international experience and export performance of SMEs in Brazil. International Business Review. doi:10.1016/j.ibusrev.2015.12.002

Pla-Barber, J., Alegre, J., 2007. Analysing the link between export intensity, innovation and firm size in a science-based industry. International Business Review 16, 275-293. doi:10.1016/j.ibusrev.2007.02.005

PME 2011 - Rapport sur lévolution des PME, 2011. BPIFrance, observatoire des PME.

Raymond, L., St-Pierre, J., 2013. Strategic capability configurations for the internationalization of SMEs: A study in equifinality. Int. Small Bus. J. 31, 82-102. doi:10.1177/0266242610391325

Rejeb, H.B., Morel-Guimarães, L., Boly, V., Assiélou, N.G., 2008. Measuring innovation best practices: Improvement of an innovation index integrating threshold and synergy effects. Technovation 28, 838-854. doi:10.1016/j.technovation.2008.08.005

Rodrigues, J.F., Traina, A.J.M., de Oliveira, M.C.F., Traina, A.J.M., 2006. Reviewing Data Visualization: an Analytical Taxonomical Study, in: Tenth International Conference on Information Visualization, 2006. IV 2006. Presented at the Tenth International Conference on Information Visualization, 2006. IV 2006, pp. 713-720. doi:10.1109/IV.2006.94

Rodriguez, R.P., Hechanova, M.R.M., 2014. A Study of Culture Dimensions, Organizational Ambidexterity, and Perceived Innovation in Teams. Journal of Technology Management \& Innovation 9, 21-33. Roper, S., Love, J.H., 2002. Innovation and export performance: evidence from the UK and German manufacturing plants. Research Policy 31, 1087-1102. doi:10.1016/S0048-7333(01)00175-5 
Salomon, R.M., Shaver, J.M., 2005. Learning by Exporting: New Insights from Examining Firm Innovation. Journal of Economics \& Management Strategy 14, 431-460. doi:10.1111/j.1530-9134.2005.00047.x

Sepulveda, J., Gonzalez, J., Camargo, M., Alfaro, M., 2010. A metrics-based diagnosis tool for enhancing innovation capabilities in SMEs. International Journal of Computers, Communications and Control 5, Pages 919-928.
Skupin, A., Fabrikant, S.I., 2003. Spatialization Methods: A Cartographic Research Agenda for Non-geographic Information Visualization. Cartography and Geographic Information Science 30, 99-119. doi:10.1559/152304003100011081

Van Beveren, I., Vandenbussche, H., 2010. Product and process innovation and firms' decision to export. Journal of Economic Policy Reform 13, 3-24.

Yau, N., 2012. Visualize This! John Wiley \& Sons. 